\title{
СПЕЦИФИКА ПРОФЕССИОНАЛЬНОЙ КОМПЕТЕНТНОСТИ В ОБЛАСТИ ПРОЕКТНО-ЭКОНОМИЧЕСКОЙ ДЕЯТЕЛЬНОСТИ БУДУЩИХ МАГИСТРОВ ЭКОНОМИКИ
}

В статье рассиатривается суичость и структура профессиональной компетентности в области проектно-экономической деятельности будуцих магистров экономики. Показано, что эта профессиональная компетентность интегрирует профессиональные знания, уиения и личностные качества, необходимые для создания, сопровождения и оценки эффективности проектных реиений, и выступает в виде комплекса различного рода профессионально-поведенческих и личностных качесте и способностей. В структуру профессиональной компетентности включены когнитивньй, мотивационно-иенностный, поведенческий и рефлексивный компоненты, содержательное наполнение которых отражсат специфику проектно-экономической деятельности будуцих магистров.

Ключевые слова: компетентность, профессиональная компетентность, проектно-экономическая деятельность, магистры экономики, структура профессиональной компетентности.

\section{Nikolay Simonov \\ SPECIFICITY OF PROFESSIONAL COMPETENCE IN PROJECT AND ECONOMIC ACTIVITY OF FUTURE MASTERS OF ECONOMICS}

The article presents a review of the nature and structure of professional competence in project and economic activity of future economic masters. It is shown that professional competence integrates professional knowledge, skills and personal qualities necessary for the creation, support and evaluation of the design solutions effectiveness, and presents as a set of different kinds of professional-behavioral and personal qualities and abilities. The structure of professional competence includes cognitive, motivational, value, behavioral and reflexive components, the content of which reflects the specifics of the design and economic activities of future masters.

Key words: competence, professional competence, project and economic activity, masters of economics, structure of professional competence.

Bведение / Introduction. Формирование профессиональной компетентности у будущих магистров экономики происходит в вузе в рамках формирования основных характеристик и отдельных элементов и видов их будущей профессиональной деятельности. В работах А. П. Болозович, Е. М. Езерской, А. Е. Ильина, Ю. В. Казаченок, Н. Г. Козловой, Л. Г. Лапаева, Н. В. Максименко, И. В. Мироненко, С. Мэн, Я. С. Чистовой, М. Н. Янушевской и др. [3; 5; 7 и др.], посвящённых исследованию особенностей формирования профессиональных компетенций будущих экономистов, проектно-экономической деятельности и связанным с ней профессиональным компетентностям уделяется минимальное внимание. Недостаточно исследована сущность и составляющие профессиональной компетентности в области проектно-экономической деятельности, условия и особенности её формирования в рамках учебного процесса вуза, специфика моделирования этого процесса для результативного усвоения соответствующих профессиональных компетенций. Авторы называют проектную компетентность основным и особым, особенным видом профессиональной компетентности специалистов экономического профиля. Внимание же при работе с магистрантами-экономистами в основном уделяется научно-исследовательской и аналитической деятельностям, наиболее полно отражающим специфику высшего образования на уровне магистратуры как углубленной исследовательской ступени обучения студентов. При этом заметим, акцент делается на углубление исследовательских и аналитических умений и способностей, пусть и с учётом специфики экономи- 
ческой профессии, тем самым ставится во главу угла не профессионально ориентированная подготовленность, а значит не конкурентоспособность выпускника, а его потенциал как исследователя, т. е. акцентируется вариант академической, а не прикладной магистратуры.

Между тем, на наш взгляд, проектно-экономическая деятельность как производная от общей проектной деятельности максимально полно отвечает смыслу будущей профессиональной деятельности экономиста как со стороны специфики профессиональной сферы, так и со стороны цельности решаемой задачи, представленной в виде проекта (как отражения единицы деятельности - действия).

Pезультаты и обсуждение / Results and discussion. Возобновление в Новейшей истории практики подготовки магистров в российских вузах началось с подготовки профессионалов-экономистов. К особенностям профессиональной деятельности современного экономиста относятся её многообразие, комплексность, творческий характер, что обусловливает необходимость формирования на этапе обучения в вузе организационно-управленческих, проектно-технологических, маркетинговых, аналитических, экспериментально-исследовательских, консалтинговых, информационных и других профессиональных компетенций. Требования к магистрам экономических направлений подготовки связаны с научно-методическим обеспечением процесса формирования этих профессиональных компетенций, позволяющих реализовывать их в профессиональной деятельности.

Формирование профессиональной деятельности у студента происходит в зависимости от её вида и через дифференциацию соответствующих каждому виду профессиональных компетенций. Эти последние, как показано нами ранее [11], представляют собой сочетание знаний и готовности к деятельности, способности справляться с различными профессиональными задачами, при этом они реализуются в рамках профессиональной компетентности.

Приобретение будущими магистрами экономики определённого уровня профессиональной компетентности уже в процессе обучения в вузе рассматривается как приоритетное направление совершенствования их профессиональной подготовки. Важным показателем профессиональной компетентности как образовательного результата является способность будущего экономиста решать задачи, определяемые условиями реальной профессиональной деятельности.

В исследованиях Р. В. Батуриной, А. М. Каунова, О. Г. Максимовой, Л. А. Харитонова, К. С. Хоружего и др. $[1 ; 6 ; 8 ; 14$ и др.] описаны требования к профессиональной компетентности будущего магистра экономики: он должен владеть экономической культурой, социальной и эмоциональной компетентностью, основами менеджмента и маркетинга, стратегиями развития экономического мышления, приёмами развития исследовательских умений и способностей к проектной деятельности, готовности к выполнению предпринимательских функций, готовности к работе в ситуации перманентной неопределённости и риска, эффективной деятельности в условиях инноваций.

Особого внимания заслуживают проектные компетенции и виды деятельности экономиста, что обусловлено как потребностями практики, поскольку выполненная экономистом профессиональная задача зачастую в своей результирующей части обладает характеристиками проекта, так и интенсификацией и популяризацией в целом в образовании проектного подхода («метода проектов) (Е. С. Полат [9])). К причине такого масштабного взгляда на проектирование относят приобретающую всё большую актуальность в современной науке социально-проектную парадигму, которая развивает представление о проектировании как способе методологической работы и принципе организации практической деятельности в образовании. Значение социально-проектной парадигмы повышается в связи с тем, что проектирование всё в большей степени рассматривается как способ построения системы теоретического знания, которая через соответствующие технологии усвоения формирует новые реальности социальной практики (С. В. Павловская, Н. Г. Сироткина, Н. Л. Стенина [10]).

Мы рассматриваем сущность и структуру профессиональной компетентности в области проектно-экономической деятельности у будущих магистров экономики с позиции необходимости формирования у них совокупности компетенций, указанных в ФГОС ВО. В связи с этим обращаем внимание на следующее. 
Выпускник, освоивший программу магистратуры, в соответствии с проектно-экономическим видом профессиональной деятельности должен быть готов решать следующие профессиональные задачи: подготовка заданий и разработка проектных решений с учётом фактора неопределённости; подготовка заданий и разработка методических и нормативных документов, а также предложений и мероприятий по реализации разработанных проектов и программ; подготовка заданий и разработка системы социально-экономических показателей хозяйствующих субъектов; составление экономических разделов планов предприятий и организаций различных форм собственности; разработка стратегии поведения экономических агентов на различных рынках. Применительно к проектно-экономической деятельности во ФГОС высшего образования у выпускника магистратуры в области экономики прописывается необходимость формирования следующих профессиональных компетенций:

- способность самостоятельно осуществлять подготовку заданий и разрабатывать проектные решения с учётом фактора неопределённости, разрабатывать соответствующие методические и нормативные документы, а также предложения и мероприятия по реализации разработанных проектов и программ (ПК-5);

- способность оценивать эффективность проектов с учётом фактора неопределённости (ПК-6);

- способность разрабатывать стратегии поведения экономических агентов на различных рынках (ПК-7).

В процессе формирования этих компетенций у магистрантов не только повышается специальная грамотность, способность формулировать и решать прикладные задачи, но и - на основе межпредметных связей и реализации инновационных технологий - расширяется кругозор и углубляются знания и умения организовывать профессиональную деятельность, применять информационные технологии в самостоятельном конструировании и проектировании содержания профессиональной деятельности.

Анализ литературы позволил нам к особенностям проектно-экономической деятельности, которые необходимо учитывать в процессе подготовки будущих магистров в области экономики, отнести следующее [12; 13]:

- междисциплинарный характер, необходимость привлечения знаний из различных учебных дисциплин, из собственного жизненного опыта или их обретения в результате исследования;

- алгоритмизацию, которая способствует овладению такими функциями, как анализ, целеполагание, планирование, организация, регулирование, контроль и прогноз;

- актуализацию профессиональных интересов студентов за счёт цельного видения профессиональной функции, включение формулируемой задачи и её решения в контекст будущей профессиональной деятельности;

- профессиональное позиционирование, обеспечивающее развитие способности студентов к выполнению профессиональных функций в связи с комплексным характером проектных заданий, близостью его структуры к реальной проектной деятельности, готовности к решению экономических проблем в ситуациях реальной действительности.

Е. А. Снигирёва, исследуя проектную деятельность будущих экономистов, отмечает, что эта деятельность выступает как новый и особый вид профессиональной деятельности, который связан с исследованием, проектированием, моделированием, анализом и регламентацией бизнес-процессов компании. Автор определяет профессиональные компетенции в области проектной деятельности будущего экономиста как систему знаний, умений и навыков, личностных качеств, которая предполагает [12]:

- умение определять этапы, сроки, ресурсы для ведения проекта по описанию бизнес-процессов в организации;

- способность анализировать проблемы, риски проекта;

- предлагать решение проблем в ходе проекта и др. 
Говоря о профессиональных компетенциях, мы определяем их как сочетание знаний, умений, способностей и качеств личности, которые обеспечивают выполнение профессиональной деятельности. В этом смысле экономист в рамках своей профессиональной деятельности, принимая решения, действует на основании сформированных у него определённых профессионально-важных качеств, и через них реализует профессиональные компетенции. Обобщение результатов теоретической рефлексии авторов позволил нам предварительно объединить следующим образом качества и способности, относящиеся к профессиональным компетенциям в области проектно-экономической деятельности у магистранта-экономиста (Р. В. Батурина, Т. Н. Ващило, И. В. Гоголева, Г. А. Гущина, О. В. Жиронкина, К. С. Хоружий и др. $[1 ; 2 ; 4 ; 8 ; 13$ и др.]): мотивационно-мобилизующие, деятельностные, информационно-коммуникативные и профессионально-рефлексивные. Заметим, что это описание отражает в меньшей степени знаниевый, а больше ценностно-смысловой, мотивационный и рефлексивный аспекты профессиональной компетентности будущего экономиста.

Подводя некоторый итог, сформулируем определение: профессиональные компетенции в области проектно-экономической деятельности будущих магистров экономики представляют собой вид их профессиональных компетенций, интегрирующих профессиональные знания, умения и личностные качества, необходимые для создания, сопровождения и оценки эффективности проектных решений, и выступающих в виде комплекса различного рода профессионально-поведенческих (специальных, технических; деятельностный аспект) и личностных (надпрофессиональных; личностный аспект) качеств и способностей.

Учитывая результаты проведённого анализа, наполнение специфичным содержанием компонентов профессиональной компетентности, выделенных нами ранее [11], на наш взгляд, должно быть следующим:

- $\quad$ для когнитивного компонента - это осведомлённость и понятийная система в области основ менеджмента и маркетинга, управления предприятием в условиях инноваций, неопределённости и риска; знание сути категорий «экономический проект» и «проектное решение) (как форма и содержание минимальной целостной единицы (действия) проектно-экономической деятельности); представление о понятиях «активы», «обязательства», «капитал», «движении денежных потоков», «доходы», «расходы», «финансовые результаты деятельности организации», «производственный процесс», «инновации», «неопределённость», «риск»; знание содержания различных стратегий поведения хозяйствующих агентов и системы социально-экономических показателей деятельности хозяйствующих субъектов; представление об экономических разделах планов предприятий и организаций различных форм собственности; знание основных этапов проектирования экономических решений и условий сопровождения проектных решений (методических, нормативных, организационных);

- $\quad$ для мотивационно-ценностного компонента - это мотивация достижения, познавательная и внутренне детерминированная профессиональная мотивация; позитивное профессиональное отношение, устойчивый интерес и понимание специфической роли проекта и проектной деятельности как формы организации решения возникающих профессиональных задач; готовность к работе в ситуации неопределённости и риска; готовность применить специальные знания по проектированию экономических решений на практике;

- для поведенческого компонента - сочетание репродуктивных, проблемно-творческих, исследовательско-познавательных действий в профессиональной деятельности; умение применять информационно-коммуникационные и интерактивные технологии; междисциплинарность и алгоритмизированность навыков проектирования, способность к переключению с одной деятельности на другую; владение навыками прогнозирова- 
ния экономических явлений и процессов; владение навыками разработки проектных решений с учётом фактора неопределённости (этапы, сроки, ресурсы), методических, нормативных документов по проекту, организации проектных мероприятий; способность оценивать эффективность проектов;

- для рефлексивного компонента - это развитая рефлексивная культура в профессионально-экономической деятельности в целом - навыки контроля уровня знаний и развития умений для целей проектирования экономических решений и прогнозирования их последствий; стремление к профессиональному совершенству, к самореализации в сфере экономики и управления; оценка своей деятельности и оценка деятельности организации; способность к импровизации и предвидению; рефлексия собственной эффективности (ориентация на свои силы, уверенность в себе, чувство самоэффективности).

Такое представление о профессиональной компетентности в области проектно-экономической деятельности будущего магистра экономики позволяет подойти к диагностике профессиональных компетенций, их формированию и развитию в рамках специальной модели и педагогических условий, реализуемых в условиях образовательного процесса.

Заключение/Conclusion. Проектно-экономическая деятельность максимально полно отвечает смыслу будущей профессиональной деятельности магистра экономики как со стороны специфики профессиональной сферы, так и со стороны цельности решаемой задачи, представленной в виде проекта. К особенностям проектно-экономической деятельности, которые необходимо учитывать в процессе профессиональной подготовки будущих магистров в области экономики, относятся междисциплинарный характер, алгоритмизация, актуализация профессиональных интересов студентов за счёт цельного видения профессиональной функции, профессиональное позиционирование.

Профессиональные компетенции в области проектно-экономической деятельности будущих магистров экономики представляют собой вид их профессиональных компетенций, интегрирующих профессиональные знания, умения и личностные качества, необходимые для создания, сопровождения и оценки эффективности проектных решений, и выступающих в виде комплекса различного рода профессионально-поведенческих и личностных качеств и способностей.

Компоненты профессиональной компетентности содержательно включают в себя когнитивный компонент (обще- и специально-профессиональные знания и представления об экономическом проектировании, проектных решениях и проектно-экономической деятельности хозяйствующего субъекта); мотивационно-ценностный компонент (позитивное профессиональное отношение к проектной деятельности как форме организации решения возникающих задач в ситуации неопределённости и риска), поведенческий компонент (сочетанный характер деятельности по планированию и прогнозированию экономических явлений и процессов, междисциплинарность и алгоритмизированность в навыках проектирования и разработки проектных решений) и рефлексивный компонент (развитая рефлексивная культура в области профессионально-экономической деятельности, оценка и самооценка своей деятельности и деятельности организации, способность к импровизации и предвидению).

\section{ЛИТЕРАТУРА И ИНТЕРНЕТ-РЕСУРСЫ}

1. Батурина Р. В. Формирование общенаучной компетенции у будущих экономистов в процессе математической подготовки: автореф. дис... канд. пед. наук. Казань, 2012. 23 с.

2. Гущина Г. А. Профессиональная культура экономиста: история, теория и практика. Киров, 2009. 159 с.

3. Езерская Е. М. Формирование готовности будущего бакалавра к управлению производственно-технологическими рисками: дис. ... канд. пед. наук. Оренбург, 2015. 165 с.

4. Жиронкина О. В. Формирование профессионально-значимых качеств будущих экономистов в процессе изучения общеобразовательных дисциплин: автореф. дис. ... канд. пед. наук. Кемерово, 2003. 20 с. 
5. Ильин А. Е. Профессионально-личностное развитие будущих менеджеров сферы управления в процессе изучения иностранных языков: автореф. дис. ... канд. пед. наук. Йошкар-Ола, 2016. 24 с.

6. Кадирова Г. А. Особенности формирования профессиональных компетентностей будущих экономистов в вузах республики Таджикистан: дис. ... канд. пед. наук. Душанбе, 2018. 149 с.

7. Казаченок Ю. В. Формирование культуры конкурентных отношений будущих экономистов: дис. ... канд. пед. наук. Челябинск, 2016. 26 с.

8. Максимова О. Г., Харитонова Л. А. Формирование профессиональной компетентности будущих экономистов в условиях современного вуза // Вестник Томского государственного педагогического университета. 2009. № 11. С. 17-23.

9. Полат Е. С. Новые педагогические и информационные технологии в системе образования / Е. С. Полат, М. Ю. Бухаркина, М. В. Моисеева, А. Е. Петров. М., 2003. 272 с.

10. Павловская С. В., Сироткина Н. Г. Анализ опыта проектной деятельности при преподавании управленческих дисциплин в вузах // Современные проблемы науки и образования. 2014. № 4. URL: https://science-education.ru/ru/article/view?id=13864 (дата обращения: 21.08.2018).

11. Симонов Н. В. Сущность и структура профессиональной компетентности: анализ подходов и определение понятий // Вестник Северо-Кавказского федерального университета. Научный журнал. 2018. № 1 (64). С. 186-192.

12. Снигирёва Е. А. Формирование конкурентоспособности будущих экономистов на основе проектной деятельности в процессе профессиональной подготовки: дис. ... канд. пед. наук. Киров, 2016. 249 с.

13. Совершенствование подготовки магистров экономики и менеджмента для АПК России: материалы межвуз. научно-практ. семинара / под ред. В. Т. Водянникова, Е. В. Худяковой. М., 2013. 74 с.

14. Хоружий К. С. Профессиональная компетентность будущих экономистов: сущность и содержание [Электронный ресурс] // Современные проблемы науки и образования. 2014. № 6. URL: http:// science-education.ru/ru/article/view?id=16753 (дата обращения: 04.09.2018).

\section{REFERENCES AND INTERNET RESOURCES}

1. Baturina R. V. Formirovanie obshchenauchnoj kompetencii u budushchih ehkonomistov v processe matematicheskoj podgotovki (Formation of meta-scientific competence of future economists in the process of mathematical training): avtoref. dis... kand. ped. nauk. Kazan', 2012, 23 p.

2. Gushchina G. A. Professional'naya kul'tura ehkonomista: istoriya, teoriya i praktika (Professional culture of the economist: history, theory and practice). Kirov, 2009, 159 p.

3. Ezerskaya E. M. Formirovanie gotovnosti budushchego bakalavra k upravleniyu proizvodstvennotekhnologicheskimi riskami (Formation of readiness of future bachelors to the management of industrialtechnological risk): dis. ... kand. ped. nauk. Orenburg, 2015, 165 p.

4. ZHironkina O. V. Formirovanie professional'no-znachimyh kachestv budushchih ehkonomistov v processe izucheniya obshcheobrazovatel'nyh disciplin (Formation of professionally significant qualities of future economists in the process of meta-subjects studying): avtoref. dis. ... kand. ped. nauk. Kemerovo, 2003, $20 \mathrm{~s}$.

5. Il'in A. E. Professional'no-lichnostnoe razvitie budushchih menedzherov sfery upravleniya v processe izucheniya inostrannyh yazykov (Professional and personal development of future managers in the field of management in the process of learning foreign languages): avtoref. dis. ... kand. ped. nauk. Joshkar-Ola, $2016,24 \mathrm{p}$.

6. Kadirova G. A. Osobennosti formirovaniya professional'nyh kompetentnostej budushchih ehkonomistov v vuzah respubliki Tadzhikistan (Features of formation of professional competences of future economists in higher education institutions of the Republic of Tajikistan): dis. ... kand. ped. nauk. Dushanbe, 2018, 149 p.

7. Kazachenok YU. V. Formirovanie kul'tury konkurentnyh otnoshenij budushchih ehkonomistov (Formation of competitive relations culture of future economists): dis. ... kand. ped. nauk. CHelyabinsk, 2016, 26 p.

8. Maksimova O. G., HaritonovaL. A. Formirovanie professional'noj kompetentnostibudushchihehkonomistov $\mathrm{v}$ usloviyah sovremennogo vuza (Formation of professional competence of future economists in the conditions of modern University) // Vestnik Tomskogo gosudarstvennogo pedagogicheskogo universiteta. 2009. No 11. P. 17-23. 
9. Polat E. S. Novye pedagogicheskie i informacionnye tekhnologii v sisteme obrazovaniya (New pedagogical and information technologies in the education system) / E. S. Polat, M. YU. Buharkina, M. V. Moiseeva, A. E. Petrov. M., 2003. 272 p.

10. Pavlovskaya S. V., Sirotkina N. G. Analiz opyta proektnoj deyatel'nosti pri prepodavanii upravlencheskih disciplin v vuzah (Analysis of the project experience in teaching management subjects in the universities) // Sovremennye problemy nauki i obrazovaniya. 2014. No 4. URL: https://science-education.ru/ru/article/ view?id=13864 (data obrashcheniya: 21.08 .2018 ).

11. Simonov N. V. Sushchnost' i struktura professional'noj kompetentnosti: analiz podhodov i opredelenie ponyatij (The essence and structure of professional competence: analysis of approaches and definition of concepts) // Vestnik Severo-Kavkazskogo federal'nogo universiteta. Nauchnyj zhurnal. 2018. No 1 (64). P. $186-192$.

12. Snigiryova E. A. Formirovanie konkurentosposobnosti budushchih ehkonomistov na osnove proektnoj deyatel'nosti v processe professional'noj podgotovki (Formation of competitiveness of future economists on the basis of project activity in the process of professional training): dis. ... kand. ped. nauk. Kirov, 2016. 249 p.

13. Sovershenstvovanie podgotovki magistrov ehkonomiki i menedzhmenta dlya APK Rossii (Improving the training of masters of Economics and management for agriculture of Russia): materialy mezhvuz. nauchnoprakt. seminara / pod red. V. T. Vodyannikova, E. V. Hudyakovoj. M., 2013, 74 p.

14. Horuzhij K. S. Professional'naya kompetentnost' budushchih ehkonomistov: sushchnost' i soderzhanie (Professional competence of future economists: essence and content) [EHlektronnyj resurs] // Sovremennye problemy nauki i obrazovaniya. 2014. No 6. URL: http://science-education.ru/ru/article/view?id=16753 (data obrashcheniya: 04.09.2018).

\section{СВЕДЕНИЯ ОБ АВТОРЕ}

Симонов Николай Владимирович, соискатель кафедры социальных технологий Института образования и социальных наук СКФУ. E-mail: simonoff_nik@mail.ru.

\section{INFORMATION ABOUT AUTHOR}

Simonov Nikolay, PhD applicant (pedagogic), Department of social technologies, North-Caucasus Federal University. E-mail: simonoff_nik@mail.ru 